Res., Soc. Dev. 2019; 8(6):e3386945

ISSN 2525-3409 | DOI: http://dx.doi.org/10.33448/rsd-v8i6.945

\title{
Semente de Moringa Oleífera como solução alternativa para o tratamento de água em
} comunidades rurais

Seed of Moringa Oleifera as an alternative solution for the treatment of water in rural communities

Semilla de la Moringa Oleifera como solución alternativa para el tratamiento del agua en comunidades rurales

Recebido: 19/03/2019 | Revisado: 22/03/2019 | Aceito: 29/03/2019 | Publicado: 30/03/2019

Andresa Regina Arthuso dos Santos

ORCID: https://orcid.org/0000-0002-3599-2754

Universidade do Estado de Minas Gerais, Brasil

E-mail: andresa_arthuso@ @otmail.com

Larissa Aparecida da Cruz

ORCID: https://orcid.org/0000-0003-4531-4874

Universidade do Estado de Minas Gerais, Brasil

E-mail: larissaap95@gmail.com

Hebert Medeiros Gontijo

ORCID: https://orcid.org/0000-0002-8504-0452

Universidade do Estado de Minas Gerais, Brasil

E-mail: hebert.gontijo@uemg.br

\section{Resumo}

Esse estudo objetivou encontrar uma dose de pó preparado a partir da semente de Moringa Oleífera, que seja eficiente na remoção da turbidez da água utilizada para abastecimento humano na comunidade rural de Capela Branca, localizada na cidade de Bela Vista de Minas. Foi preparada uma solução com a semente da planta. O experimento foi realizado em um Jar Test, onde primeiramente adicionou-se em cada jarro do equipamento as respectivas quantidades da solução preparada: $5 \mathrm{~mL}, 10 \mathrm{~mL}, 15 \mathrm{~mL}, 20 \mathrm{~mL}, 25 \mathrm{~mL}$ e $30 \mathrm{~mL}$. Aumentouse a solução adicionada inicialmente nos jarros, para as respectivas quantidades: $20 \mathrm{~mL}, 40$ $\mathrm{mL}, 60 \mathrm{~mL}, 80 \mathrm{~mL}, 100 \mathrm{~mL}$ e $120 \mathrm{~mL}$. Posteriormente aumentou-se novamente a solução para: $30 \mathrm{~mL}, 60 \mathrm{~mL}, 90 \mathrm{~mL}, 120 \mathrm{~mL}, 150 \mathrm{~mL}$ e $180 \mathrm{~mL}$. Visto que nos três primeiros experimentos não houve eficiência na remoção da turbidez, os jarros foram esvaziados e apenas 4 deles foram enchidos novamente para o novo teste. Em cada um dos 4 jarros foram 
adicionados respectivamente: $0,2160 \mathrm{~g}, 0,432 \mathrm{~g}, 0,648 \mathrm{~g}$ e $0,864 \mathrm{~g}$ do pó de semente de Moringa Oleífera juntamente com $10 \mathrm{~mL}$ da solução preparada inicialmente. Foi possível perceber que o terceiro jarro, onde adicionou-se 0,648 g de pó de semente de Moringa Oleífera, demonstrou eficiência da remoção da turbidez de $2 \mathrm{~L}$ de água. Conclui-se que quantidade do pó que garantiu eficiência na remoção da turbidez $(0,648 \mathrm{~g})$ equivale a aproximadamente 3 sementes trituradas, e doses maiores ou menores, não atuam com eficiência na remoção da turbidez.

Palavras-chave: Turbidez; Jar Test; pó.

\begin{abstract}
This study aimed to find a dose of powder prepared from the Moringa Oleífera seed, which is efficient in removing turbidity from water used for human consumption in the rural community of Capela Branca, located in the city of Bela Vista de Minas. A solution was prepared with the plant seed. The experiment was carried out in a Jar Test, where the respective quantities of the prepared solution were first added to each jar of the solution: 5 $\mathrm{mL}, 10 \mathrm{~mL}, 15 \mathrm{~mL}, 20 \mathrm{~mL}, 25 \mathrm{~mL}$ and $30 \mathrm{~mL}$. The solution initially added to the jars was added to the respective amounts: $20 \mathrm{~mL}, 40 \mathrm{~mL}, 60 \mathrm{~mL}, 80 \mathrm{~mL}, 100 \mathrm{~mL}$ and $120 \mathrm{~mL}$. Afterwards the solution was again raised to: $30 \mathrm{~mL}, 60 \mathrm{~mL}, 90 \mathrm{~mL}, 120 \mathrm{~mL}, 150 \mathrm{~mL}$ and 180 $\mathrm{mL}$. Since in the first three experiments there was no efficiency in turbidity removal, the jars were emptied and only 4 of them were filled again for the new test. In each of the 4 jars were added respectively: $0.2160 \mathrm{~g}, 0.432 \mathrm{~g}, 0.648 \mathrm{~g}$ and $0.884 \mathrm{~g}$ of the Moringa Oleifera seed powder together with $10 \mathrm{ml}$ of the initially prepared solution. It was possible to notice that the third jar, where $0.648 \mathrm{~g}$ of Moringa Oleífera seed powder was added, demonstrated the efficiency of the turbidity removal of $2 \mathrm{~L}$ of water. It is concluded that the amount of the powder that guarantees turbidity removal efficiency $(0.648 \mathrm{~g})$ is equivalent to approximately 3 crushed seeds, and higher or lower doses do not work efficiently to remove turbidity.
\end{abstract}

Keywords: Turbidity; Jar Test; powder.

\title{
Resumen
}

Este estudio objetivó encontrar una dosis de polvo preparado a partir de la semilla de Moringa Oleífera, que sea eficiente en la remoción de la turbidez del agua utilizada para abastecimiento humano en la comunidad rural de Capela Branca, ubicada en la ciudad de Bela Vista de Minas. Se preparó una solución con la semilla de la planta. El experimento fue realizado en un Jar Test, donde primero se añadió en cada jarro del equipo las respectivas 
cantidades de la solución preparada: $5 \mathrm{~mL}, 10 \mathrm{~mL}, 15 \mathrm{~mL}, 20 \mathrm{~mL}, 25 \mathrm{~mL}$ y $30 \mathrm{~mL}$. Se aumentó la solución agregada inicialmente en los jarros, para las respectivas cantidades: 20 $\mathrm{mL}, 40 \mathrm{~mL}, 60 \mathrm{~mL}, 80 \mathrm{~mL}, 100 \mathrm{~mL}$ y $120 \mathrm{~mL}$. Posteriormente se aumentó nuevamente la solución para: $30 \mathrm{~mL}, 60 \mathrm{~mL}, 90 \mathrm{~mL}, 120 \mathrm{~mL}, 150 \mathrm{~mL}$ y $180 \mathrm{~mL}$. Dado que en los tres primeros experimentos no hubo eficiencia en la remoción de la turbidez, los jarros fueron vaciados y sólo 4 de ellos fueron llenados nuevamente para la nueva prueba. En cada una de las 4 jarras se añadieron respectivamente: 0,2160g, 0,432g, 0,648g y 0,864 g del polvo de semilla de Moringa Oleífera junto con $10 \mathrm{~mL}$ de la solución preparada inicialmente. Fue posible percibir que la tercera jarra, donde se añadió 0,648 g de polvo de semilla de Moringa Oleífera, demostró eficiencia de la remoción de la turbidez de 2L de agua. Se concluye que la cantidad de polvo que garantizó eficiencia en la remoción de la turbidez $(0,648 \mathrm{~g})$ equivale a aproximadamente 3 semillas trituradas, y dosis mayores o menores, no actúan con eficiencia en la remoción de la turbidez.

Palabras clave: Turbidez; Jar Test; polvo.

\section{Introdução}

A água potável é um bem natural de extrema importância na garantia da saúde da população, o que torna essencial a gestão adequada dos sistemas de abastecimento. A oferta de água que atenda aos padrões de potabilidade estabelecidos pela legislação é direito humano inquestionável. Entretanto, no Brasil ainda existe um déficit quanto a universalização desses serviços.

A população residente em localidades distantes das áreas urbanas são as mais atingidas pelo déficit nos serviços de saneamento. Conforme Censo Demográfico (2010), existem cerca de 29,9 milhões de pessoas residentes em áreas rurais no Brasil, totalizando 8,1 milhões de domicílios aproximadamente (IBGE, 2010). De acordo com os dados da Pesquisa Nacional por Amostra de Domicílios - PNAD (PNAD/2014), apenas 34,5\% das habitações rurais estão ligados a redes de abastecimento de água com ou sem canalização interna, e no restante $(65,5 \%)$, a captação de água ocorre a partir de fontes alternativas, geralmente inadequadas para consumo humano, como de chafarizes e poços, ou diretamente de cursos de água sem tratamento (IBGE, 2010).

A água advinda de tais fontes alternativas comuns no meio rural pode apresentar elevada turbidez. De acordo com Von Sperling (1996) a turbidez é determinada pelo grau de interferência com a passagem de luz através da água, atribuindo um aspecto turvo à 
mesma. Tal parâmetro está inserido na portaria 2914/2011 do Ministério da Saúde como um dos indicadores físicos da qualidade da água destinada ao consumo humano, assumindo o valor máximo permitido de 5 NTU.

Henriques, Oliveira, Meira, Fernandes, \& Feitas, (2012), afirmam que a turbidez é resultante da presença de sólidos em suspensão (matéria orgânica e inorgânica). $O$ fator negativo da turbidez é que ela pode servir de meio suporte a microrganismos patogênicos presente na massa líquida, podendo prejudicar a saúde dos indivíduos que utilizam águas turvas, além de gerar reprovação da população devido a sua aparência "barrenta".

A Moringa oleífera é uma espécie vegetal, pertencente à família Moringaceae, natural do nordeste indiano, distribuída de forma ampla em países como a Índia, Egito, Filipinas, Ceilão, Tailândia, Malásia, Burma, Paquistão, Singapura, Jamaica e Nigéria. De fácil cultivo e adaptação no Brasil, principalmente na região do Nordeste (Arantes, Ribeiro, \& Paterniani, 2012). As sementes de tal planta têm sido empregadas no tratamento de águas brutas e efluentes, atuando com eficiência na clarificação de águas turvas (Borgo, Dellacqua, Diaz, Cardoso, Motta, \& Bispo, 2016).

O tratamento da água a partir da semente de Moringa Oleífera ocorre devido a presença de proteínas de baixo peso molecular que em contato com a água adquirem carga positiva que atraem partículas carregadas negativamente como silte e argila, essa atração forma flocos densos que sedimentam (Paterniani, Mantovani, \& Sant'Anna, 2009). O tratamento da água com a semente triturada pode ser utilizado em locais variados, a baixo investimento e sem o uso de energia elétrica. O procedimento, apesar de simples garante eficiência na remoção de até $90 \%$ da turbidez e das bactérias presentes no meio (Borgo et al., 2016).

Desse modo, esse estudo objetivou encontrar uma dose de pó preparado a partir da semente de Moringa Oleífera, que seja eficiente na remoção da turbidez da água utilizada para abastecimento humano na comunidade rural de Capela Branca, localizada na cidade de Bela Vista de Minas.

\section{Metodologia}

Segundo Ritcher e Netto (1991), a coagulação é o processo em que adiciona-se o coagulante na água a fim de reduzir as forças que tendem manter separadas as partículas em suspensão. Por sua vez, a floculação, é a aglomeração dessas partículas, formando flocos, por meio de transporte de fluido, fornecendo condições através de tempo de detenção e 


\section{Res., Soc. Dev. 2019; 8(6):e3386945}

ISSN 2525-3409 | DOI: http://dx.doi.org/10.33448/rsd-v8i6.945

intensidade de agitação, para aumentar o tamanho dos flocos, de modo a facilitar sua sedimentação.

Com o intuito de verificar a eficiência da semente de Moringa Oleífera como um coagulante natural atuante na remoção da turbidez da água proveniente de uma nascente, utilizada para abastecer uma parcela da comunidade Capela Branca em Bela Vista de Minas, foi realizada uma coleta de água no dia 13/11/2018 de aproximadamente 50 L (litros) de água em uma das residências abastecidas, em um dia ensolarado e sem chuva nas últimas 24 horas.

Os testes de laboratório foram realizados no Departamento de Água e Esgoto de João Monlevade (DAE/JM). Foram realizadas leituras da turbidez, cor e pH da água, a fim de reduzir os valores encontrados através do tratamento com a semente de Moringa Oleífera.

Ndabigengesere e Narasiah (1998), afirmam que as sementes de Moringa Oleífera descascadas garantem uma melhor eficiência em relação as não descascadas. Desse modo, primeiramente as sementes foram descascadas, como mostra a Figura 1.

Figura 1: Sementes de Moringa Oleífera descascadas

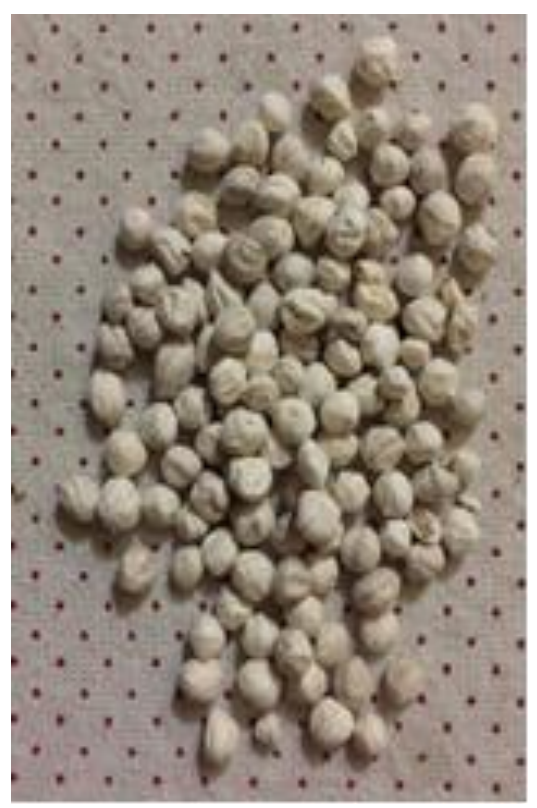

Fonte: Autores, 2018

A Figura representa as Sementes de Moringa Oleíferas após o processo manual de retiramento das cascas.

Dando continuidade, as sementes foram trituradas com o auxílio de um liquidificador e, posteriormente o resultante desse processo foi peneirado, a fim de se homogeneizar o tamanho das partículas (Figura 2). 
Res., Soc. Dev. 2019; 8(6):e3386945

ISSN 2525-3409 | DOI: http://dx.doi.org/10.33448/rsd-v8i6.945

Figura 2: Pó preparado a partir da semente de Moringa Oleífera

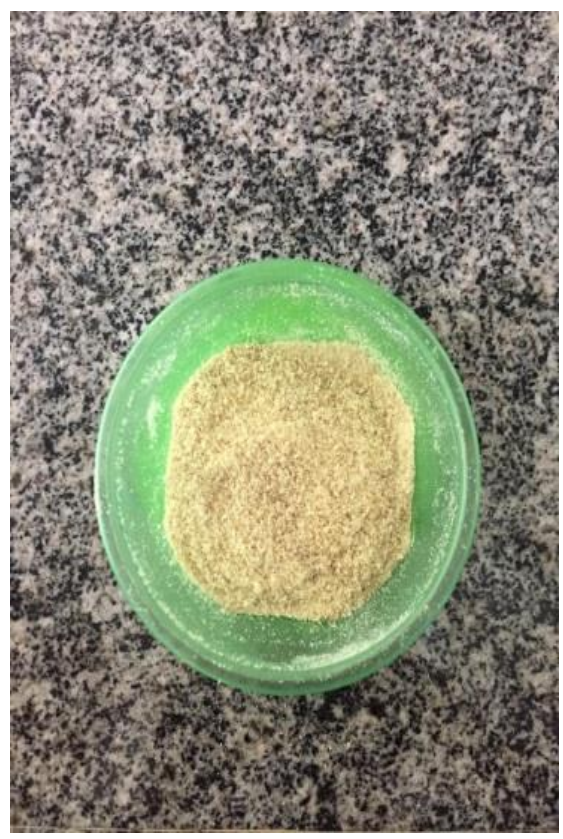

Fonte: Autores, 2018.

A Figura representa o pó resultante das sementes de Moringa Oleífera, após serem trituradas e peneiradas.

De acordo com a literatura, a semente de Moringa oleífera é eficiente na remoção da cor e turbidez da água, desse modo, a intenção desse experimento foi utilizar quantidades arbitrárias do pó, a fim de verificar a eficiência na mudança das características da água e se as quantidades utilizadas já seriam suficientes na remoção da turbidez.

No intuito de assemelhar o experimento à realidade das áreas rurais, visto que nem todos os indivíduos possuem balança, inicialmente o coagulante natural não foi pesado, utilizou-se uma pequena colher para medir a quantidade, de modo que o pó preenchesse toda a concha e retirando os excessos (Figura 3).

Figura 3: Colher utilizada como medidor de pó de semente de Moringa Oleífera 


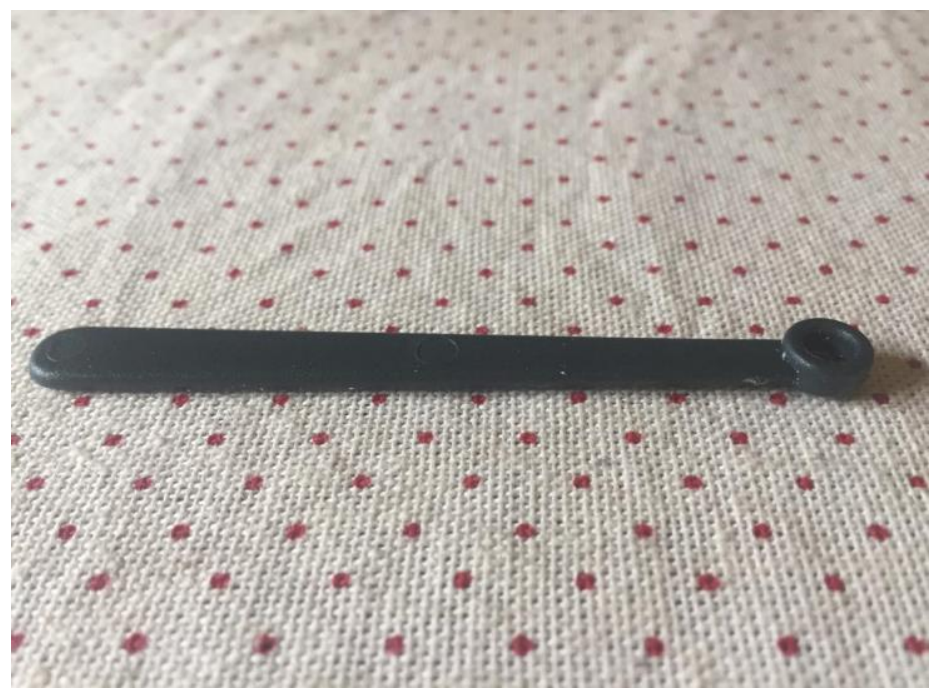

Fonte: Autores, 2018

A Figura representa a colher empregada como base indicadora da quantidade de pó de Semente de Moringa Oleífera, utilizado nos experimentos de redução de cor e turbidez da água da localidade em estudo.

Pesou-se a quantidade de pó da colher utilizada, chegando a um valor de 0,0773 g. Para o preparo da solução inicial, utilizou-se 5 colheres, obtendo o um valor de 0,3865 g. Em um béquer, foi adicionada a quantidade de pó de semente de Moringa Oleífera estipulada previamente $(0,3865 \mathrm{~g})$ em $100 \mathrm{~mL}$ de água destilada, misturou-se com o auxílio de um bastão formando uma solução que, posteriormente foi transferida para um balão, onde completou-se de água destilada até $1 \mathrm{~L}$.

Para os ensaios de coagulação/floculação utilizou-se o equipamento Jar Test, a fim de se determinar a dosagem ótima do coagulante na remoção de cor e turbidez da água.

O Jar Test é composto por 6 jarros e em cada um deles, foi adicionado $2 \mathrm{~L}$ da água em tratamento. Posteriormente, adicionou-se nos jarros a solução preparada inicialmente em quantidades equivalentes a respectivamente: $5 \mathrm{~mL}, 10 \mathrm{~mL}, 15 \mathrm{~mL}, 20 \mathrm{~mL}, 25 \mathrm{~mL}$ e $30 \mathrm{~mL}$. Utilizou-se o equipamento por 20 minutos, em agitação a $43 \mathrm{rpm}$ (rotações por minutos). Logo após, cada jarro permaneceu em repouso por 30 minutos para sedimentação, e em seguida verificou-se os valores de turbidez.

Aumentou-se a solução adicionada inicialmente nos jarros, para as respectivas quantidades: $20 \mathrm{~mL}, 40 \mathrm{~mL}, 60 \mathrm{~mL}, 80 \mathrm{~mL}, 100 \mathrm{~mL}$ e $120 \mathrm{~mL}$, deixando o Jar Test em agitação por 10 minutos. Em seguida aumentou-se novamente a solução em cada jarro para: $30 \mathrm{~mL}, 60 \mathrm{~mL}, 90 \mathrm{~mL}, 120 \mathrm{~mL}, 150 \mathrm{~mL}$ e $180 \mathrm{~mL}$, utilizando o Jar Test por mais 10 minutos. Observou-se de forma visual se ocorreram mudanças nas características da água. 
Dando continuidade ao experimento, os jarros foram esvaziados, lavados e enchidos novamente com 2 litros da água a serem tratadas. Dessa vez, foram utilizados apenas 4 dos 6 jarros do Jar Test. A quantidade de pó de semente de Moringa Oleífera utilizada nessa nova fase do experimento foi mais uma vez arbitrária e medida através de uma pequena tampa (Figura 4).

Figura 4: Tampa como medidor de pó de semente de Moringa Oleífera

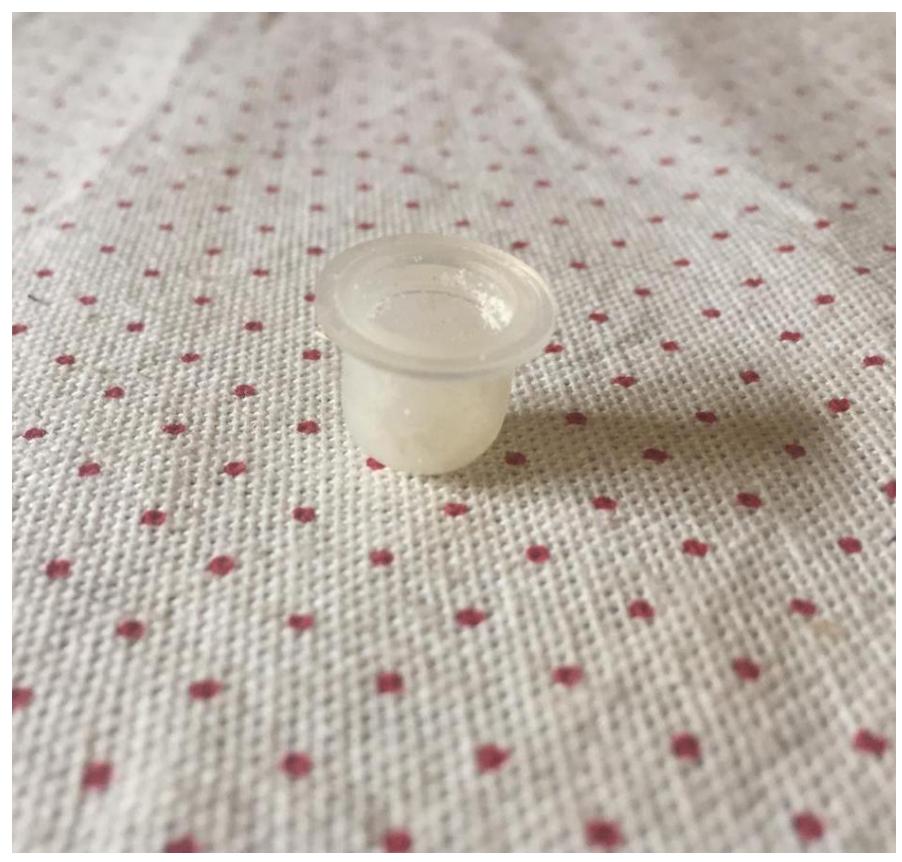

Fonte: Autores, 2018.

A Figura representa a tampa empregada como base indicadora da quantidade de pó de Semente de Moringa Oleífera, utilizado nos experimentos de redução de cor e turbidez da água da localidade em estudo.

Pesou-se a quantidade de pó que preenche cada tampa, correspondendo ao valor de 0,2160 g. Desse modo, foram adicionados em cada um dos 4 jarros do equipamento, $10 \mathrm{~mL}$ da solução preparada inicialmente, juntamente com o pó de semente de Moringa Oleífera preparado. A quantidade de pó adicionado em cada jarro corresponde a respectivamente: 1 tampa (0,2160g), 2 tampas $(0,432 \mathrm{~g}), 3$ tampas $(0,648 \mathrm{~g})$ e 4 tampas $(0,864 \mathrm{~g})$. Utilizou-se o Jar Test por 20 minutos e posteriormente realizou-se a leitura da turbidez em diferentes tempos de decantação, sendo respectivamente: 30 minutos, 90 minutos e 270 minutos. Para o último tempo (270 minutos), passou-se a água do jarro $3 \mathrm{em}$ um papel de filtro e mediu-se a turbidez novamente. 


\section{Resultados}

A Tabela 1 representa os valores obtidos e os valores máximos permitidos pela portaria 2914/2011 do Ministério da Saúde, em relação aos parâmetros cor, pH e turbidez da água bruta residencial, coletada no dia 13/11/2018, antes dos testes com a semente de Moringa Oleífera.

Tabela 1: Resultado das análises físico-químicas para a caixa d'água de uma residência abastecida pela nascente em estudo.

\section{PARÂMETROS}

\section{VMP}

VALORES

\section{RESIDENCIAL}

\begin{tabular}{l|ll}
\hline COR (PCU) & 15 & 220,0 \\
PH & 6 a 9 & 6,82 \\
TURBIDEZ (NTU) & 5 NTU & 24,2 NTU
\end{tabular}

Fonte: Autores, 2018.

De acordo com a Tabela, o pH encontra-se em conformidade com a legislação, enquanto parâmetros cor e turbidez apresentam valores maiores que o máximo permitido. A desconformidade entre os valores encontrados e o máximo permitido pela legislação, pode ser responsável por ocasionar doenças de veiculação hídrica para a população que utiliza tal água para abastecimento.

Em relação aos ensaios de coagulação/floculação no Jar Test, foram realizados inicialmente 3 experimentos, com diferentes quantidades da solução preparada, a fim se obter a concentração ideal de coagulante e assim reduzir a turbidez, uma vez que a leitura inicial desse parâmetro indicou o valor de 24,2 NTU, encontrando-se em quantidades maiores que o máximo permitido pela legislação, que é de 5 NTU.

No primeiro teste, em cada jarro do equipamento, utilizou-se a solução preparada com o pó de semente de Moringa Oleífera em quantidades equivalentes a respectivamente: $5 \mathrm{~mL}$, $10 \mathrm{~mL}, 15 \mathrm{~mL}, 20 \mathrm{~mL} ; 25 \mathrm{~mL}$ e $30 \mathrm{~mL}$. Após o funcionamento do aparelho durante 20 minutos e posteriormente 30 minutos de decantação da água, de forma visual, foi possível perceber que não houve formação de flocos e nem mudança nas características da água em nenhum dos jarros, apontando que não houve eficiência no experimento, o que foi 
comprovado após a leitura da turbidez, que indicou para todos os jarros valores semelhantes a leitura da turbidez inicial, antes do experimento. Os resultados obtidos para turbidez em cada jarro após o tempo de decantação estão representados na Tabela 2, enquanto a Figura 5 representa a análise visual do experimento realizado.

Tabela 2: Resultado das análises da turbidez em cada jarro, após primeiro teste

JARRO

SOLUÇÃO (ML)

TURBIDEZ (NTU)

\begin{tabular}{|l|ll}
\hline $\mathbf{1}$ & 5 & 23,4 \\
$\mathbf{2}$ & 10 & 22,4 \\
$\mathbf{3}$ & 15 & 23,1 \\
$\mathbf{4}$ & 20 & 23,9 \\
$\mathbf{5}$ & 25 & 22,9 \\
$\mathbf{6}$ & 30 & 22,9 \\
\hline
\end{tabular}

Fonte: Autores, 2018.

A Tabela mostra o valor de turbidez encontrado em cada jarro, após o primeiro ensaio de coagulação/floculação. Os valores encontrados se assemelham ao valor da turbidez inicial da água, antes do teste, indicando que não houve eficiência no experimento.

Figura 5: Resultado visual da análise de turbidez em cada jarro, após o primeiro teste 


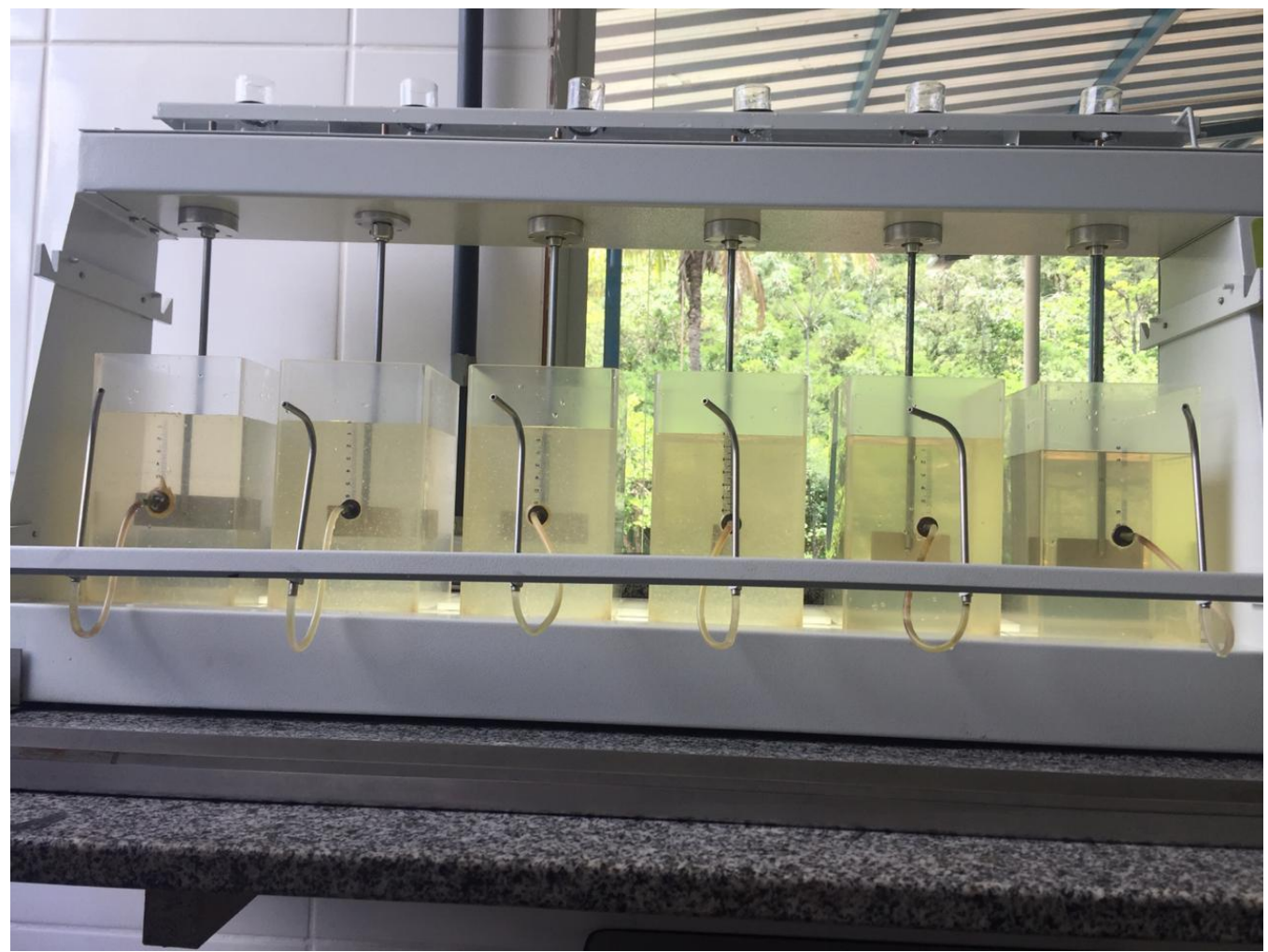

Fonte: Autores, 2018.

A partir da imagem é possível observar a água contida em todos os jarros está turva. Desse modo, de forma visual pode-se concluir que o primeiro teste realizado não foi eficaz na remoção de turbidez da água em nenhum dos jarros.

Nas duas novas tentativas de reduzir a turbidez da água a partir da solução preparada de semente de Moringa Oleífera, aumentou-se as quantidades de solução em cada jarro para respectivamente: $20 \mathrm{~mL}, 40 \mathrm{~mL}, 60 \mathrm{~mL}, 80 \mathrm{~mL}, 100 \mathrm{~mL}$ e $120 \mathrm{~mL}$ e posteriormente para respectivamente: $30 \mathrm{~mL}, 60 \mathrm{~mL}, 90 \mathrm{~mL}, 120 \mathrm{~mL}, 150 \mathrm{~mL}$ e $180 \mathrm{~mL}$. Após o tempo de funcionamento do Jar Test e o tempo de decantação utilizados para as duas novas tentativas, a partir de análise visual foi possível perceber que nos dois casos não houveram a formação de flocos e nenhuma mudança nas características da água, indicando que novamente não houve sucesso no experimento. A Figura 6 representa o resultado do segundo teste, quanto a Figura 7 retrata o resultado do terceiro teste.

Figura 6: Resultado visual da análise de turbidez em cada jarro, após o segundo teste 
Res., Soc. Dev. 2019; 8(6):e3386945

ISSN 2525-3409 | DOI: http://dx.doi.org/10.33448/rsd-v8i6.945

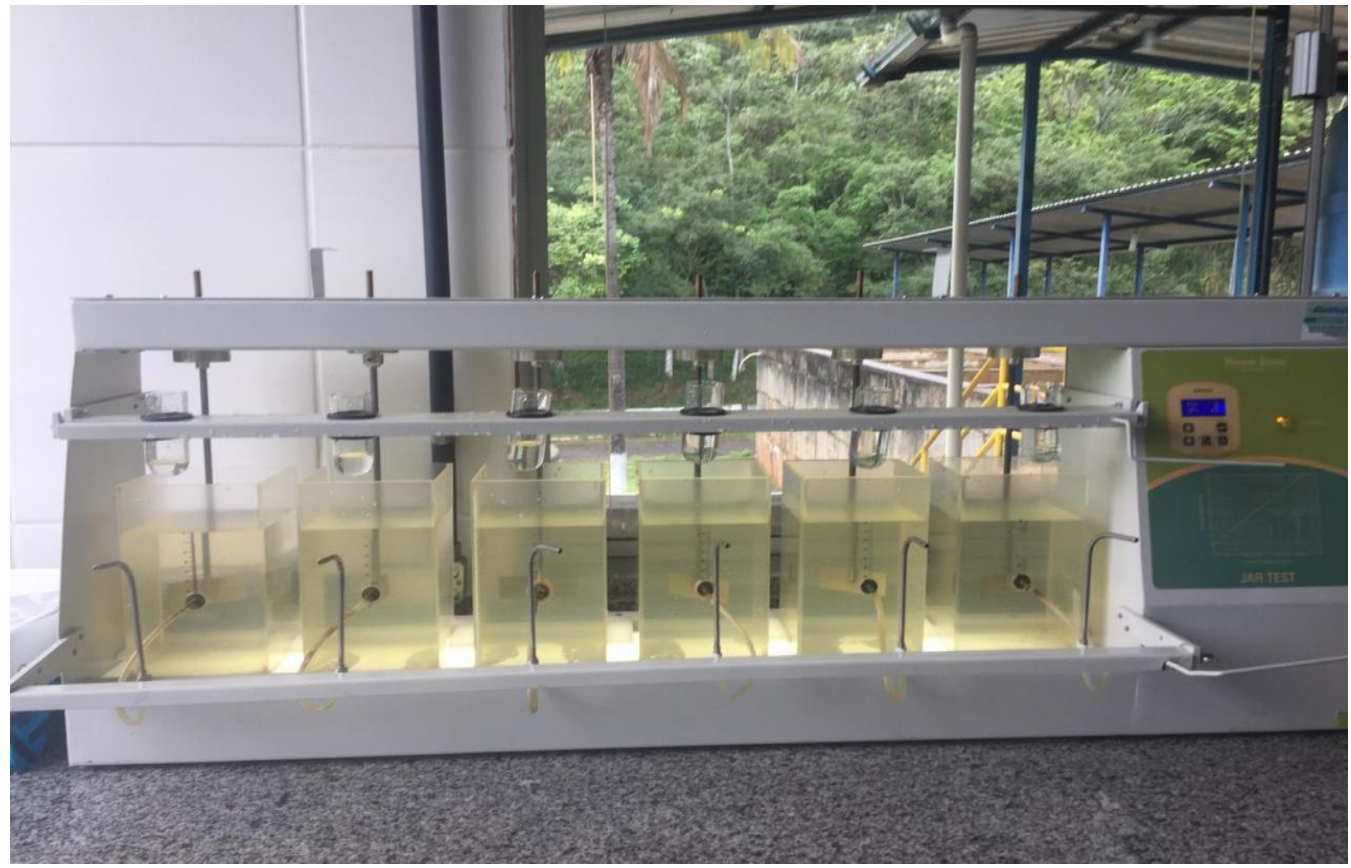

Fonte: Autores, 2018.

A partir da imagem é possível observar a água contida em todos os jarros está turva. Desse modo, de forma visual pode-se concluir que o segundo teste realizado não foi eficaz na remoção de turbidez da água em nenhum dos jarros.

Figura 7: Resultado visual da análise de turbidez em cada jarro, após o terceiro teste

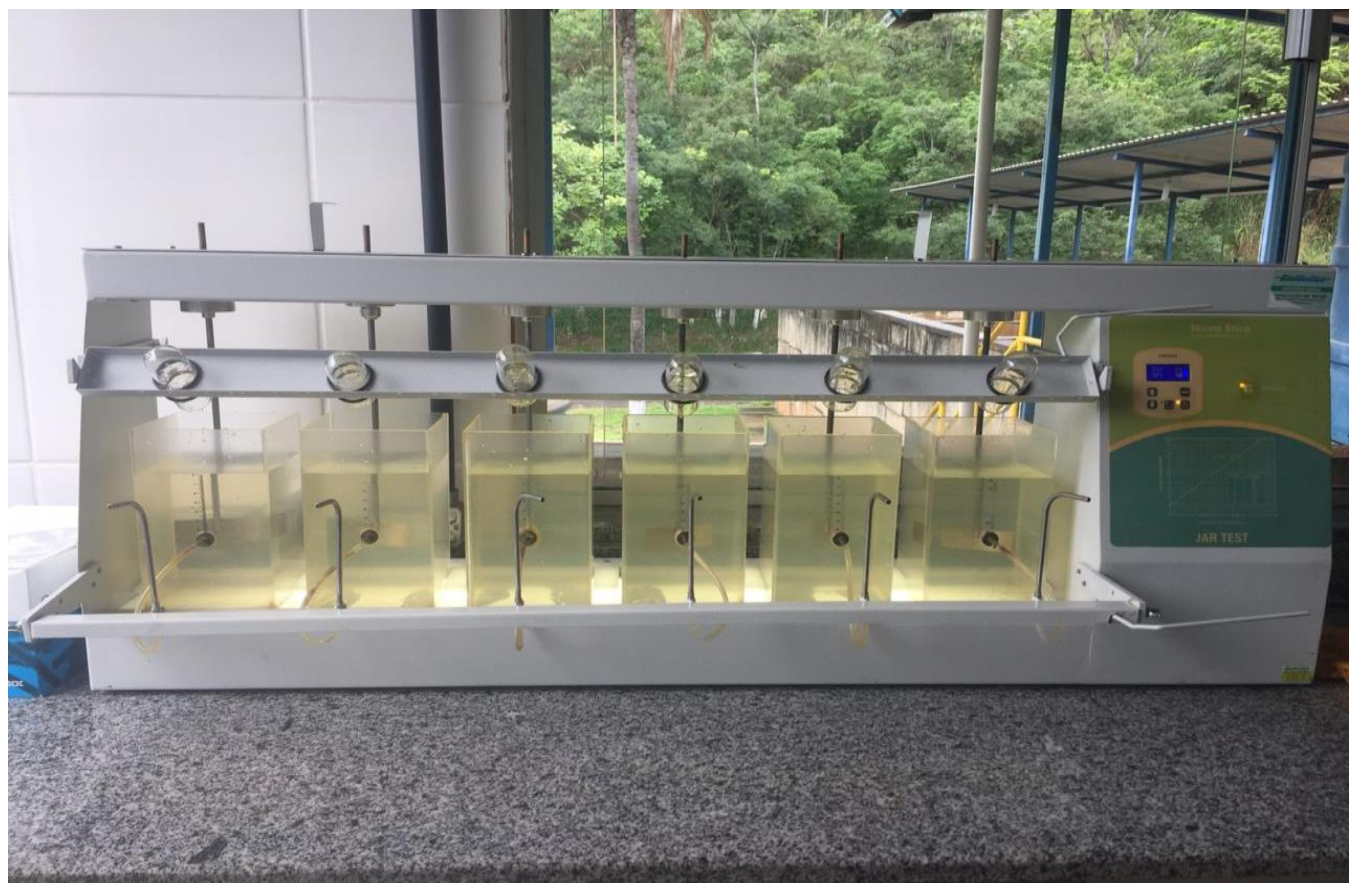

Fonte: Autores, 2018.

A partir da imagem é possível observar a água contida em todos os jarros está turva. Desse modo, de forma visual pode-se concluir que o terceiro teste realizado não foi eficaz na remoção de turbidez da água em nenhum dos jarros. 
Com o insucesso dos três experimentos realizados, foi possível perceber que a concentração da solução preparada não foi suficiente para remoção da turbidez. Desse modo, houve a necessidade de repetir o experimento com concentrações maiores da solução. Assim, os jarros foram esvaziados e apenas 4 deles foram enchidos novamente para o novo teste. Em cada um dos 4 jarros foram adicionadas quantidades distintas, respectivamente: 0,2160g, 0,432g, 0,648g e 0,864g do pó de semente de Moringa Oleífera juntamente com 10 $\mathrm{mL}$ da solução preparada inicialmente. A partir do novo teste, foram obtidos valores distintos para os parâmetros físico-químicos da água de acordo com a variação do tempo, a Tabela 3 indica os resultados das análises físico-químicas após 30 minutos de decantação, a Tabela 4 representa os resultados após 90 minutos de decantação, enquanto a Tabela 5 retrata os resultados após 270 minutos de decantação.

Tabela 3: Resultado das análises físico-químicas do teste 4, após 30 minutos de decantação

JARRO

$\mathbf{1}$
$\mathbf{2}$
$\mathbf{3}$
$\mathbf{4}$

Fonte: Autores, 2018.
PH 7,0

6,7

6,58

6,57
TURBIDEZ

24,4

29,9

13,9

43,9
COR

130

270

120

310

Após 30 minutos de decantação não houve mudança significativa nos valores de cor e turbidez nos jarros 1 e 2. No jarro 3, houve diminuição nos valores de cor e turbidez, indicando eficiência do experimento. No jarro 4 os valores de cor e turbidez aumentaram, apontando efeito contrário ao esperado com o experimento.

Tabela 4: Resultado das análises físico-químicas do teste 4, após 90 minutos de decantação 


\begin{tabular}{l|ll}
\hline $\mathbf{1}$ & 24,7 & 190 \\
$\mathbf{2}$ & 33,1 & 220 \\
$\mathbf{3}$ & 6,15 & 40 \\
$\mathbf{4}$ & 41,5 & 310 \\
\hline
\end{tabular}

Fonte: Autores, 2018.

Após 90 minutos de decantação não houve mudança significativa nos valores de cor e turbidez nos jarros 1 e 2. No jarro 3, houve diminuição nos valores de cor e turbidez, indicando eficiência do experimento. No jarro 4 os valores de cor e turbidez aumentaram, apontando efeito contrário ao esperado com o experimento.

Tabela 5: Resultado das análises físico-químicas do teste 4, após 270 minutos de decantação

\section{JARRO}

\begin{tabular}{l|l|}
\hline $\mathbf{1}$ & 25 \\
$\mathbf{2}$ & 31,3 \\
$\mathbf{3}$ & 3,78 \\
$\mathbf{4}$ & 50,9 \\
\hline
\end{tabular}

Fonte: Autores, 2018.

Após 270 minutos de decantação não houve mudança significativa nos valores de turbidez nos jarros 1 e 2. No jarro 3 a turbidez diminuiu e atingiu um valor abaixo do máximo permitido pela legislação, o que indicou eficiência do experimento. No jarro 4 o valor da turbidez aumentou, apontando efeito contrário ao esperado com o experimento. $\mathrm{O}$ parâmetro Cor não foi medido novamente pois a última leitura para o último tempo de decantação (270 minutos) foi realizada no laboratório da UEMG, onde não havia o aparelho Colorímetro.

$\mathrm{O}$ pH não foi medido continuamente, pois em todos os testes realizados, incluindo a análise preliminar, anterior aos experimentos, esse parâmetro se encontra de acordo com o 


\section{Res., Soc. Dev. 2019; 8(6):e3386945}

ISSN 2525-3409 | DOI: http://dx.doi.org/10.33448/rsd-v8i6.945

padrão permitido pela Portaria 2.914/11 do Ministério da Saúde, que define valores ideais entre 6 e 9.

Com esse experimento, foi possível perceber que de todos os jarros, o terceiro, onde adicionou-se 0,648 g de pó de semente de Moringa Oleífera, demonstrou eficiência da remoção da turbidez da água, diferentemente dos jarros 1, 2 e 4. A Figura 8 mostra o resultado visualmente.

Figura 8: Resultado visual do experimento para redução de turbidez

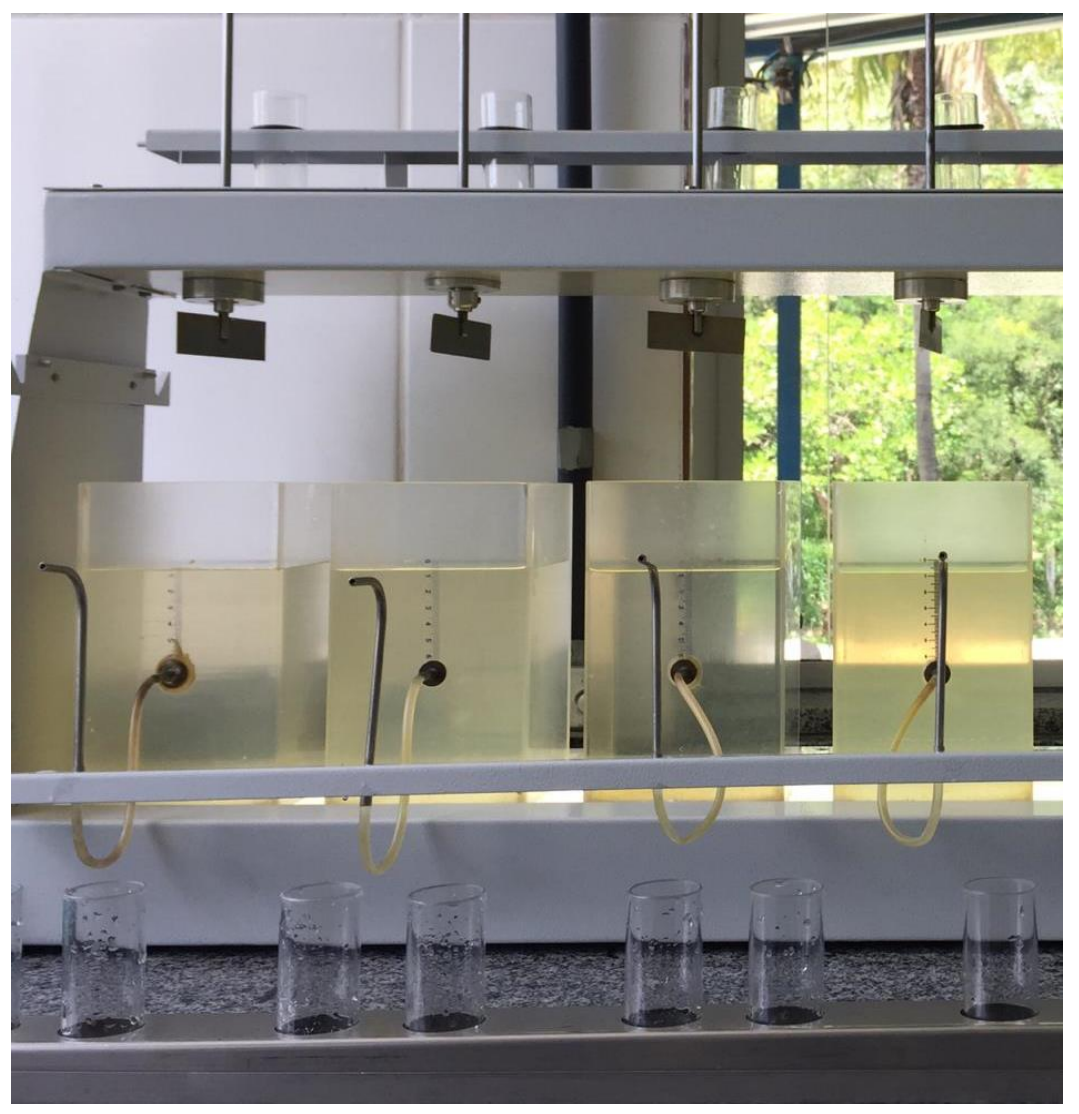

Fonte: Autores, 2018

A partir da figura é possível perceber que houve a clarificação da água no terceiro jarro, indicando redução da turbidez.

Na última leitura realizada na água desse jarro, efetuada após 4 horas e 30 minutos de decantação depois da agitação no Jar Test, o parâmetro atingiu o valor de 3,78 NTU e atendeu o padrão de potabilidade definido Portaria 2.914. Para a verificação de uma maior eficiência, filtrou-se a água do jarro 3 em um filtro de papel e mediu-se novamente a turbidez da água, o que levou novamente a diminuição da turbidez da água para 2,21 NTU. 


\section{Res., Soc. Dev. 2019; 8(6):e3386945}

ISSN 2525-3409 | DOI: http://dx.doi.org/10.33448/rsd-v8i6.945

Desse modo, comprovou-se a eficiência da semente de Moringa Oleífera para remoção da turbidez da água que abastece uma parcela da população da comunidade Capela Branca.

Com a evolução do tempo de leitura, o jarro 4 demonstrou que ao se adicionar uma quantidade de coagulante maior que a quantidade ideal, pode-se causar um efeito contrário ao desejado, aumentando a turbidez ao invés de diminuir.

Desse modo, pode-se concluir que, quanto maior o tempo em que a água permanecer em repouso (podendo ser de um dia pro outro), a remoção de coloração e turbidez fica cada vez mais visível e precisa. A Figura 9 mostra a água de tratamento dos 4 jarros após um dia de repouso, respectivamente, destacando-se o terceiro copo (esquerda para direita):

Figura 9: Água de cada um dos 4 jarros após o experimento com Semente Moringa Oleífera, respectivamente.

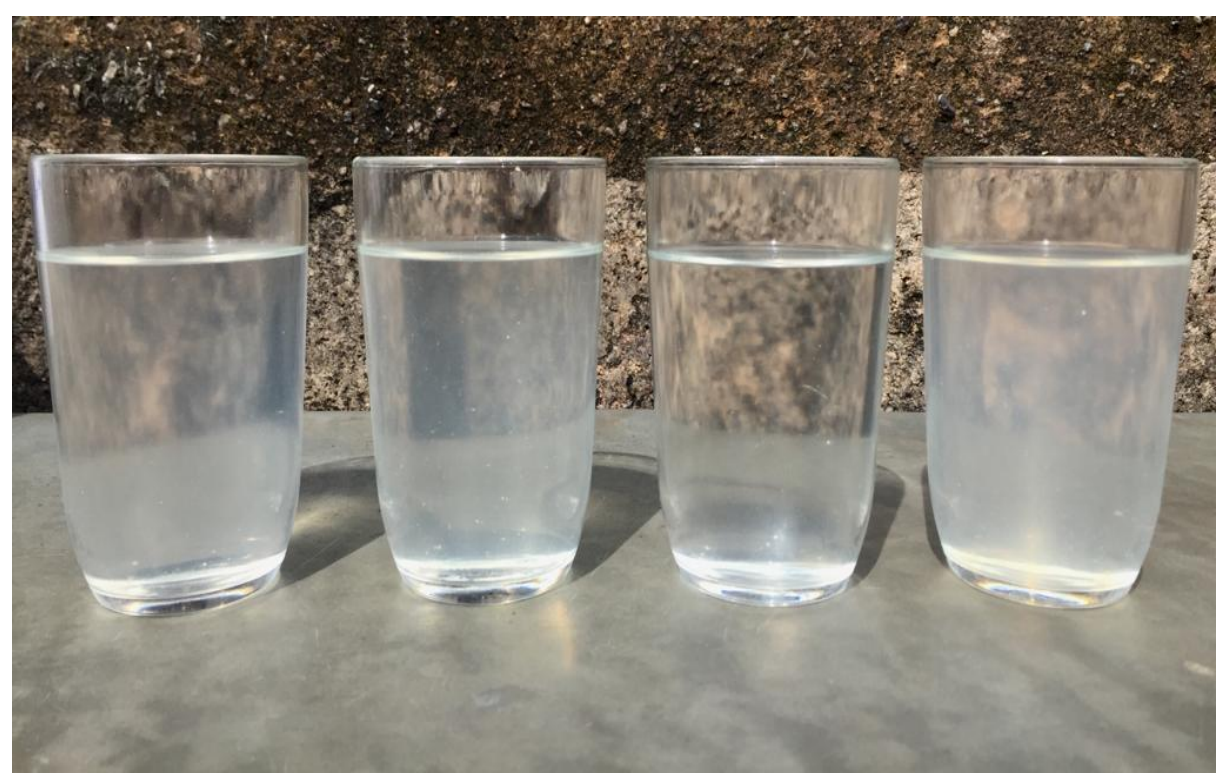

Fonte: Autores, 2018.

A partir da imagem é possível perceber a redução da cor e turbidez da água contida no terceiro copo, respectivamente, indicando eficiência do experimento com a semente de Moringa Oleífera.

Devido ao sucesso do experimento na remoção da turbidez da água no jarro 3, propõese o uso da Semente de Moringa oleífera na comunidade. O sistema proposto é adequado às comunidades rurais devido ao baixo custo e simplicidade operacional. Porém, para atingir os benefícios esperados e atuar como saneamento descentralizado, é essencial a adequada operação e utilização da dose ideal de acordo com o nível de turbidez da água, pois como foi mostrado nos experimentos realizados, doses maiores ou menores não atuam com eficiência na remoção da turbidez da água. 
De acordo com Cangela (2014) as sementes descascadas podem assumir pesos de $0,1754 \mathrm{~g}$ e 0,2274 $\mathrm{g}$, assim para se atingir as 0,648 g, que foi a dose ideal para esse estudo no tratamento de 2 litros de água, estima-se o uso de aproximadamente 3 sementes trituradas para a remoção da turbidez de 2 litros de água.

\section{Considerações Finais}

A partir da análise preliminar da água que abastece a área em estudo, foi possível perceber que os parâmetros cor e turbidez estão acima do permitido pela legislação, o que pode interferir da saúde dos moradores locais. Desse modo, essa pesquisa contribui com uma possibilidade de tratamento de água a partir da semente de Moringa Oleífera, que se destaca por ser de forma natural, individual e a baixo custo, atuando na garantia da saúde da população local.

De acordo com os experimentos realizados, pode-se concluir que a quantidade ideal de pó que garantiu eficiência na remoção da turbidez da água da localidade em estudo, foi de 0,648 g de pó para o tratamento de $2 \mathrm{~L}$ de água, tal quantidade do pó equivale a aproximadamente 3 sementes trituradas. Foi possível perceber que doses maiores ou menores do coagulante natural, não atuam com eficiência na remoção da turbidez.

Para futuros trabalhos, recomenda-se o estudo da água de outras comunidades rurais que não sejam atendidas pelos serviços convencionais de saneamento. E que a partir das pesquisas realizadas se determine doses ideias de pó de semente de Moringa Oleífera para o tratamento, de acordo com o nível de turbidez da água que abastece tais localidades.

\section{Referências}

Arantes, C. C., Ribeiro, T. A., \& Paterniani, J. E. (2012). Processamento de sementes de Moringa oleifera utilizando-se diferentes equipamentos para obtenção de solução coagulante. Revista Brasileira de Engenharia Agrícola e Ambiental.

Borgo, C., Dellacqua, G. S., Diaz, H. S. L., Cardoso, H. F. G., Motta, L. T. A., \& Bispo, Y. M. (2016). Tratamento de água com semente de Moringa oleifera. Blucher Proceedings-V Semana De Engenharia QUÍMICA UFES. Graduação em Engenharia Química, Universidade Federal do Espírito Santo, Alegre, ES, Brasil. 
Cangela, G. L. C. D. (2014). Tratamento de água para consumo humano em comunidades rurais com utilização de moringa oleifera e desinfecção solar.

Henriques, J. A., de Oliveira, R., Meira, C. M. B. S., Fernandes, M. S. M., \& de Feitas, C. C. Potencial de remoção de turbidez de água para o abastecimento de comunidades rurais com o uso da Moringa oleifera Lam. SIMPÓSIO BRASILEIRO DE CAPTAÇÃO E MANEJO DE ÁGUA DA CHUVA, 8 .

IBGE. (2010). Pesquisa Nacional por Amostra de Domicílios. Banco de Dados Agregados (PNAD). Disponível em: <http://www.sidra.ibge.gov.br/pnad/pnadpb>

Ndabigengesere, A., \& Narasiah, K. S. (1998). Quality of water treated by coagulation using Moringa oleifera seeds. Water research, 32(3), 781-791.

Paterniani, J. E., Mantovani, M. C., \& Sant'Anna, M. R. (2009). The use of Moringa oleifera seeds for treatment of surface water. Revista Brasileira de Engenharia Agrícola e Ambiental, 13(6), 765-771.

Richter, C. A., Netto, J. M. A. (1991). Tratamento de água-tecnologia atualizada. São Paulo: Editora Edgard Blücher Ltda.

Von Sperling, M. (1996). Introdução à qualidade das águas e ao tratamento de esgotos (Vol. 1). Editora UFMG.

\section{Porcentagem de contribuição de cada autor no manuscrito}

Andresa Regina Arthuso dos Santos - 50\%

Larissa Aparecida da Cruz - 45\%

Hebert Medeiros Gontijo - 5\% 